The extreme daily temperatures observed between the treatments were not different (between $17^{\prime \prime}$ and $28^{\prime \prime}$ in summer and between $12^{\circ}$ and $19^{\prime \prime}$ in winter), neither the growth rates of the fattening pigs $(600 \mathrm{~g} / \mathrm{d}$ before $60 \mathrm{~kg}$ and $650 \mathrm{~g} / \mathrm{d}$ after $)$. During early fattening (the first eight weeks) the statical system seems to be better, while air conditioning by overpressure is not recommended in winter without supplementary heating. On the other hand, beyond $60 \mathrm{~kg}$ live weight the overpressure system gives better results especially in warm periods.

Because of the flow rates of the fans used in dynamic air conditioning, it is more advisable to recycle part of indoor air in order to reduce the fresh air flow especially in winter when the building is not heated.

\title{
Air conditioning in fattening pig houses : effects of air flow and air velocity
}

\author{
B. DE LA FARGE, R. GRANIER et C. TEXIER \\ Institut Technique du Porc \\ Service Batiment et Environnement \\ M.N.E., 149, rue de Bercy, F 75595 Paris Cedex 12
}

Over a period of two years, we measured the performance of growing finishing pigs subjected to various combinations of four distinct ventilation parameters : flow rate, air velocity, volume per animal and indoor air temperature. The experiments took place in the winter and the summer. They allowed to draw the following conclusions :

A too high summer flow rate, a low volume per animal, an over-ventilation in the winter without heating, a low volume per animal corrected by a high air flow rate led to lower pig performance. A high volume per animal in connection with a low summer air-flow rate, high air velocities correctly associated with indoor air temperature whatever the flow rate improved the performance. Winter heating did not satisfactorily improve the pig fattening performance which was however maintained by a correct minimum flow rate (removal of latent heat) without any heating. Under ventilation during the winter to preserve the heat emitted by the animals did not bring any advantage and was harmful to the longevity of the building.

\section{Influence of whey consumption on the pollutional load of pig manure}

\author{
Michèle HEDUIT et J.-P. MONGIN \\ G.I.D.A.-M.N.E., 149, rue de Bercy, F 75595 Paris Cedex 12 \\ I.T.P., Station expérimentale, Les Cabrières \\ F 12200 Villefranche-de-Rouergue
}

Whey is often used in bacon pig feeding for economic reasons. However, this leads to a manure very different from that of an animal fed a diet based on cereals.

Intake of a large volume of liquid by the animal results in a dilution of the manure. About 70 p. 100 of the volume of liquid (water or whey) ingested are eliminated in the form of urine. 
The amounts of mineral components and the sludge loads excreted (parameters expressed in $\mathrm{g} / \mathrm{day} /$ animal) are not significantly different according to the type of feeding and in an animal of comparable weight receiving an equivalent amount of dry matter.

The amount of excreta is highly correlated with the amount of feed ingested, but depends also on the nutrient quality. For instance, ingestion of 23 liters whey would produce an excretion of dry matter equivalent to that obtained with the ingestion of $1 \mathrm{~kg}$ flour.

\title{
Farm wastes in the Lamballe-Matignon region (Côtes-du-Nord)
}

\author{
Ildiko RAKSANYI et Y. ETESSE \\ Chambre régionale d'Agriculture \\ 111, boulevard Maréchal-de-Lattre-de-Tassigny, F 35000 Rennes \\ C.T.G.R.E.F., 17, avenue de Cucillé, F 35000 Rennes
}

The Lamballe-Matignon region has greatly developed its pig and egg production. In 27 towns, 42000 fattening sows and 240000 fattening pigs $(0.9$ fattening sow and 5 fattening pigs per ha agricultural area) and 2700000 poultry were recorded.

Taking into account all the animal species, the excreta may produce per ha agricultural area and per year $160 \mathrm{~N}$ units, $125 \mathrm{P}_{2} \mathrm{O}_{5}$ units and $120 \mathrm{~K}_{2} \mathrm{O}$ units corresponding to a complete soil fertilization. However, there are frequently losses of the fertilizing elements from animal excreta (at collection, storage and manure spreading) and a reduced efficiency on the cultures, especially for nitrogen. Moreover, the available quantities of excreta are variable depending on the towns and the farms and do not always correspond to the culture needs. For instance, 246 farms produce more than $400 \mathrm{~N}$ units/ha, which exceeds their fertilization needs. Others could use more than they produce.

An individual inquiry was made among 133 farmers possessing at least 50 fattening sows or 400 fattening pigs. Most farms have surpluses in $\mathrm{N}, \mathrm{P}_{2} \mathrm{O}_{5}$ and $\mathrm{K}_{2} \mathrm{O}$, which are still increased by the supplies of manure to neighbours and purchases of commercial fertilizers.

Soil analyses were made on 103 parcels, 79 of which had received manure regularly for at least 5 years, not the 24 others. These analyses showed the $\mathrm{P}_{2} \mathrm{O}_{5}$ and $\mathrm{K}_{2} \mathrm{O}$ enrichment of the soils due to animal excreta.

Thus, in this region savings could be made on mineral fertilizers. A better valorization of animal excreta could be obtained from a better knowledge of their fertilizing value, an improvement of pig mature quality, an increase in storage capacities and a development of exchanges between animal producers and neighbour farmers.

\section{Pig manure utilization in a region with pig production units}

\author{
O. LAPIERRE et C. BRETTE \\ Institut National Agronomique Paris-Grignon \\ Centre d'Etudes et de Recherche sur l'Economie et l'Organisation des Productions animales \\ 16, rue Claude-Bernard, F 75231 Paris Cedex 05
}

The results of an inquiry on the pig manure problem made in Brittany during the summer 1980 among 147 farmers have allowed to determine some of the components of this problem. 